\title{
The functional interaction of visual-perceptual and response mechanisms during selective attention in young adults, young-old adults, and old-old adults
}

\author{
MICHAEL P. SULLIVAN \\ Oregon Health Sciences University, Portland, Oregon
}

\begin{abstract}
A response compatibility paradigm was employed to address how the perceptual and response activation processes functionally interact during selective attention and how they may be influenced by aging. The results showed that increasing the visual similarity of targets within response sets reduced the magnitude of the interference effect, but only with a narrow interletter distance. In a dissimilar condition, the magnitude of the interference effect did not vary with age. However, in a similar condition, the magnitude of the interference effect was larger for both young (18-30 years) and young-old adults (55-79 years) than for old-old adults ( $\geq 80$ years). In contrast, all three groups showed similar facilitation effects. These results failed to provide support for the notion that enhanced spatial filtering of the target from the flankers produces a corresponding decrease in response competition. Rather, the decrease in the interference effect can be attributed to a functional interaction between the perceptual availability of partial information and the magnitude of response competition. The results also suggest that age does not impair response activation but that advanced age diminishes the availability of local, but not global, feature information.
\end{abstract}

Selective attention functions to facilitate the processing of target information that occurs in the presence of distracting or irrelevant information. This is typically studied with distractor interference tasks, which require participants to select a target in a known location that occurs in the presence of one or more nontargets (e.g., B. A. Eriksen \& C. W. Eriksen, 1974). Within these types of tasks, the distractors can slow response times to a target. Currently, there are two main sources of slowing that have been identified-one that functions within early perceptual processes and one that is associated with response selection processes.

With regard to early selection, several studies have provided evidence that is consistent with there being a competition among input channels during perceptual processing by demonstrating that responses to a target flanked by visually similar distractors are slower than responses to a target flanked by visually dissimilar distractors (Bjork \& Murray, 1977; Estes, 1972; LaBerge \&

This research was supported in part by Grant 08017 from the National Institute of Aging to the Oregon Alzheimer's Disease Center and in part by a grant from the Oregon Alzheimer's Research Alliance. I also thank Dara Wasserman, Alison Dame, and Suzanne Lehmann for assisting with the recruitment of the old-old adults, Josh Millard and Sarah Hogue for assisting with data collection, and Pierre Jolicoeur, Art Kramer, Bill Prinzmetal, Richard Ridderinkhof, and Dick Smid for their thoughtful comments on earlier versions of this manuscript. Correspondence concerning this article should be addressed to M. P. Sullivan, Aging and Alzheimer's Center, Department of Neurology, Oregon Health Sciences University, 3181 S.W. Sam Jackson Park Road, CR131, Portland, OR 97201-3098 (e-mail: sullivan@ohsu.edu).

-Accepted by previous editor, Myron L. Braunstein
Brown, 1989). To account for this slowing, LaBerge and his colleague (LaBerge, 1995; LaBerge \& Brown, 1989) proposed a model in which attention acts as a spatial filter that facilitates target identification (see, also, Coles, Gratton, Bashore, Eriksen, \& Donchin, 1985; Luck \& Hillyard, 1994; Smid, Mulder, \& Mulder, 1990). Within their model, a processing component, called the feature register, functions to extract both feature and location information from each letter presented in a stimulus array. The feature information is sent to a shape identifier that functions to extract the actual identity of the letter. In addition, there is a spatial filter that operates under topdown control (i.e., identify the center target letter) to modulate the information flow from the feature register to the shape identifier. The spatial filter functions to amplify the information flow at the target location, relative to the flanker locations. Presumably, when target-flanker similarity is low, there is little input from the spatial filter, because the function of lateral inhibitory connections that exist between similar feature representations composing the target and flanker letter identities (within the feature register) are sufficient to allow for target identification. However, as target-flanker similarity increases, the functioning of the spatial filter increases, which requires time and slows target identification.

The second source of slowing results from a competition for response activation. This occurs in two-choice response tasks in which the response compatibility of the target and distractors is varied. In the noise-compatibility paradigm developed by B. A. Eriksen and C. W. Eriksen (1974), participants are instructed to select a central target letter and to ignore flanking distractor letters. The re- 
sponse compatibility of the target and the distractors is varied across three conditions. In the compatible condition, the target and distractors share the same response (e.g., $\mathrm{HHH}$ ); in the incompatible condition, the target and distractors require opposite responses (e.g., EHE, where $E$ is also a member of the response set); and in the neutral condition, the distractors are not members of the response set (SHS). The typical finding is that response times are slower and errors are more numerous in the incompatible than in the neutral condition (i.e., an interference effect). In contrast, the response times may be faster and errors less numerous in the compatible than in the neutral condition (i.e., facilitation effect). Studies of the compatibility effects (Coles et al., 1985; Gratton, Coles, Sirevaag, Eriksen, \& Donchin, 1988; Smid, Lamain, Hogeboom, Mulder, \& Mulder, 1991) have provided support for the notion that, from the point in time in which the early perceptual processes begin computing both target and nontarget identities (LaBerge \& Brown, 1989), they are simultaneously and continuously transmitting this information to their associated responses (C.W. Eriksen \& Schultz, 1979; Miller, 1982; Smid et al., 1991). The literature suggests that there are two main processes underlying response selection. Both are considered to be centrally located and to function prior to overt motor output (De Jong, Wierda, Mulder, \& Mulder, 1988; Kopp, Rist, \& Mattler, 1996; Osman, Bashore, Coles, Donchin, $\&$ Meyer, 1992). One is stimulus-response translation, which involves the mapping between the target letters and their associated keypresses. These stimulus-response maps are established prior to the experiment. The other is response activation. That is, when one of the response channels reaches a criterion level of activation, an overt response is executed (Gratton et al., 1988; LaBerge, 1994; Smid et al., 1990; see, also, Miller, Coles, \& Chakraborty, 1996). Thus, in the incongruent condition, in which the flankers also are members of the response set, there is a competition between the two response channels that delays responding, relative to the neutral condition, in which only the target response channel is activated. In contrast, in the congruent condition, responses may be faster than in the neutral condition, because there is no competition for response activation. However, the magnitude of the facilitation effect is much smaller than that of the interference effect and is not always obtained (B. A. Eriksen \& C.W. Eriksen, 1974; Flowers, 1990).

The present study was designed to address two main questions. First, within Experiment 1, the study addressed whether the early perceptual processes underlying identification of a target that occurs in the presence of distractors functionally interact with the later processes underlying response activation. Second, Experiment 2 addressed the question of how these processes are influenced by aging.

\section{EXPERIMENT 1}

With regard to whether the early perceptual processes influence the competition for response selection, previ- ous studies have shown that decreasing the strength of the perceptual input from the flankers by increasing the target-flanker distance (B. A. Eriksen \& C. W. Eriksen, 1974; Yantis \& Johnston, 1990), increasing the size of the targets, relative to the flankers (C. W. Eriksen \& Schultz, 1979; Ridderinkhof, van der Molen, \& Bashore, 1995), masking the flankers (Schwarz \& Mecklinger, 1995), or narrowing the focus of attention around the target (LaBerge, Brown, Carter, Bash, \& Hartley, 1991) all reduce the magnitude of the interference effect. However, relatively few studies have examined the influence of target-flanker similarity on the interference effect and the possible influence of the enhanced function of the socalled spatial filter.

In a seminal study, B. A. Eriksen and C. W. Eriksen (1974) addressed the question of whether the response channels were sensitive to feature information arising from the perceptual processing of the flanker or only to identity information. As part of their stimulus set, they presented visually similar compatible arrays in which the target and flankers shared similar features (e.g., NWZ response set, and visually similar incompatible arrays in which the flankers were visually similar to a target of the opposite response set not present in the display (e.g., NWZSNWZ, where flankers are similar to the other target, $H$ ). The results implicated a role for early perceptual processing (enhanced function of the spatial filter) by showing that response times to the visually similar incompatible arrays did not differ from response times to the visually similar compatible arrays at a narrow $\left(0.06^{\circ}\right)$ interletter distance. More important, the results showed a reduction in the interference effect for the visually similar incompatible arrays, relative to an incompatible condition (e.g., HHHSHHH), which supported the notion that the response channels may be sensitive not only to identity, but to feature level information. Indeed, several studies have since replicated this finding (C. W. Eriksen \& Schultz, 1979; Miller, 1982; Osman, Bashore, Coles, Donchin, \& Meyer, 1988; Smid et al., 1991; Yeh \& Eriksen 1984; see, also, Lavie, 1997). The general explanation for this reduction has invoked the notion that the competing response channel receives less activation from feature than from identity input.

In a later study, C. W. Eriksen and B. A. Eriksen (1979, Experiment 1) varied the visual similarity of targets across response sets, to examine predictions made by the continuous flow model (C. W. Eriksen \& Schultz, 1979), as well as the interactive channels model of Estes (1972), which states that, as the number of features shared by a target and a flanker increases, the competition among their respective input channels increases and slows target identification. In their study, the target letters $\mathrm{H}$ and $\mathrm{S}$ were assigned to one response set, and the target letters $\mathrm{K}$ and $\mathrm{C}$ were assigned to the other response set and combined to form the following dissimilar and similar flanker conditions: congruent (e.g., d,

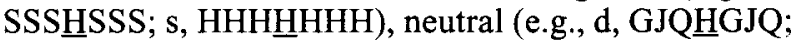

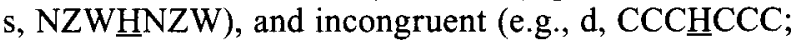


s, KKK $\underline{H K K K)}$. The results showed an effect of similarity only at a narrow (i.e., $0.06^{\circ}$ ) interletter distance. The results from the compatible condition provided support for the continuous flow model, since response times were reliably slower in the dissimilar than in the similar condition. This was attributed to response competition from the flanker letter of the same response set. In contrast, although not reliable, for both the incompatible and the neutral conditions, response times were faster in the dissimilar than in the similar condition. C. W. Eriksen and B. A. Eriksen suggested that these results were consistent with the interactive channels model, as well as with an easier Gestalt segregation of the target from the flankers in the dissimilar condition. However, C. W. Eriksen and B. A. Eriksen (1979, Experiment 1) did not use these data to address the question of whether targetflanker similarity modulated the magnitude of the interference effect.

Recently, Zeef, Sonke, Kok, Buiten, and Kenemans (1996) addressed this question directly within a response compatibility paradigm by examining whether visually similar flankers (i.e., NNHNN) would produce a greater interference effect (incongruent minus congruent) than would visually dissimilar flankers (i.e., SSHSS). In addition, they also varied the interletter distance from $0.47^{\circ}$ to $3.26^{\circ}$. The results showed no difference in the magnitude of the interference effect (incompatible minus compatible) between the similar and the dissimilar conditions. On the basis of this finding, Zeef et al. argued that the feature similarity of the target and the flankers does not contribute to the interference effect produced by incompatible flankers. However, the failure of Zeef et al. to observe a functional interaction between perceptual and response activation processes may have resulted from the fact that even the narrowest target and flanker interletter distance was considerably wide at $0.47^{\circ}$. At this distance, the common feature information may not have had an opportunity to interact and produce a perceptual confusion sufficient to require the further engagement of the spatial filter (B. A. Eriksen \& C. W. Eriksen, 1974; C. W. Eriksen \& B. A. Eriksen, 1979; LaBerge, 1995).

To address this question, Experiment 1 employed a flanker compatibility task similar to those of C. W. Eriksen and B. A. Eriksen (1979) and Zeef et al. (1996) and manipulated the visual similarity (similar, dissimilar) of the target and flankers, the interletter distance (narrow, wide), and response compatibility (congruent, incongruent, neutral). However, in order to determine whether an interaction between target-flanker similarity and the interference effect is dependent on interletter distance, the wide interletter distance was set to be equal to the smallest distance used by Zeef et al. $\left(0.47^{\circ}\right)$, and the narrow distance was set at $0.09^{\circ}$ In addition, to maximize perceptual interference, a short target display duration was included, to limit the amount of time participants had to extract identity information from the target and flankers (C. W. Eriksen \& Schultz, 1979; Schwarz \& Mecklinger, 1995).
To the extent that enhanced spatial filtering influences response activation at the narrow interletter distance, there are two possible outcomes. In both cases, the enhanced function of the spatial filter is expected to slow, rather than speed up, target identification. According to LaBerge and Brown (1989), the spatial filter is under topdown attentional control, which requires more processing time as target-flanker similarity increases. On the one hand, increasing target-flanker similarity may slow target identification and allow the incongruent flanker more time to activate the competing response (Ridderinkhof et al., 1995). On this account, the enhanced functioning of the spatial filter would facilitate target processing but would not affect the processing of the flanker identity. This would result in a larger interference effect in the similar than in the dissimilar condition. On the other hand, increasing target-flanker similarity may reduce the interference effect. That is, the enhanced function of the spatial filter may slow target identification and either reduce the perceptual processing of the flanker identity (LaBerge \& Brown, 1989), which may result in a corresponding decrease in response activation, or allow the incongruent response channel's activation to decay or receive greater suppression from the target response channel, to the extent that they mutually inhibit one another (Coles, Gehring, Gratton, \& Donchin, 1992; see, also, Gratton et al., 1988; Marteniuk \& MacKenzie, 1980). However, whether an increase in target-flanker similarity produces an increase or decrease in the interference effect is an empirical question.

\section{Method}

\section{Participants}

Fifteen young adults (mean age $=26.5$ years, $S D=4.67$ ) were recruited from Oregon Health Sciences University and Portland State University and paid $\$ 5$ for participation in the experiment. All the participants reported normal or corrected-to-normal vision.

\section{Stimuli}

The stimuli consisted of uppercase white characters presented on a black screen in Monaco 18 bold font. At a distance of $61 \mathrm{~cm}$, the letter stimuli each subtended a visual angle of $0.38^{\circ}$ horizontally and $0.52^{\circ}$ vertically. The distance between letters within the target displays was $0.09^{\circ}$ for the narrow separation condition and $0.47^{\circ}$ for the wide separation condition. Thus, the entire three-letter sequence subtended a horizontal angle of $1.32^{\circ}$ for the narrow separation condition and $2.08^{\circ}$ for the wide separation condition. The visual similarity of the target and flanker letters in the dissimilar and similar flanker conditions was based on the number of shared features, in accordance with the feature set provided by Keren and Baggen (1981). The target letters in the similar flanker condition (V, $Y$ ) shared four features, and the target letters in the dissimilar flanker condition shared no features $(Y, Q)$. The targets and flankers in the neutral conditions of the similar (YF, VF) and dissimilar (YF, $\mathrm{QF}$ ) flanker conditions shared no features.

\section{Design}

The design consisted of the within-subjects factors of flanker similarity (similar, dissimilar), interletter distance (narrow, wide), and response compatibility (congruent, incongruent, neutral). The flanker similarity conditions were blocked and the order counterbalanced across participants, so that half of the experimental trials 
required a response to targets from the similar condition $(\mathrm{Y}, \mathrm{V})$ and the other half required a response to targets from the dissimilar condition (Y, Q). The interletter distance conditions also were blocked and the order counterbalanced across participants within each flanker similarity condition. The interletter distance conditions were blocked, rather than intermixed, in an attempt to facilitate consistent processing of the target-flanker arrays. There were four possible orders for presentation of the similarity and interletter distance conditions. Each of the similarity $\times$ interletter distance blocks contained 24 congruent trials, 24 incongruent trials, and 24 neutral trials, for a total of 288 experimental trials. In the congruent condition, flanker letters were identical to the central target letter (e.g., YYY, QQQ). In the incongruent condition, the flankers letters competed with the target letter for response selection (e.g., VYV, QYQ). In the neutral condition, flankers were not associated with a response (i.e., FYF, FQF).

\section{Apparatus}

The experiment was run on a Macintosh Color Classic or Macintosh $660 \mathrm{AV}$ computer with a high-resolution 14-in. Apple color monitor. The custom software program that controlled presentation and timing of stimuli was written in Psyscript (Cohen, MacWhinney, Flatt, \& Provost, 1993). Response latencies were obtained with a Carnegie Mellon University button box containing three microswitches and a crystal oscillator that produces time measurements to within \pm 1 msec.

\section{Procedure}

The participants were tested individually in a dimly lit room and were dark adapted. First, they were given practice in mapping the target letters of the currently assigned similarity condition (i.e., $Y$, $\mathrm{Q}$ or $\mathrm{Y}, \mathrm{V})$ to their respective response keys. The $\mathrm{Ys}$ in each similarity condition were always mapped to the same key. The experimenter informed the participant of the target letter/response key mapping. Each of the target-response mapping trials consisted of the following series of events, centered in the screen: (1) a fixation cross appeared $(1,000 \mathrm{msec}) ;(2)$ one of the two target letters (Y or $\mathrm{V}$; $\mathrm{Y}$ or $\mathrm{Q}$ ) appeared randomly and remained on until a response was made; (3) feedback regarding accuracy, in the form of the written word correct or incorrect, appeared $(750 \mathrm{msec})$ and was accompanied by a simultaneous 50 -msec correct or incorrect beep; and (4) an intertrial interval occurred $(750 \mathrm{msec})$. The participants were required to attain $100 \%$ accuracy on a set of 20 target-response mapping trials before beginning the experiment.

The experimenter then presented 18 practice trials made up of 3 trials in each of the two interletter distance $\times$ three flanker conditions. On each trial within a block, the participant saw the following series of events, centered in the screen: (1) a fixation cross appeared $(1,000 \mathrm{msec}) ;(2)$ one of the three possible target-flanker displays was randomly selected and appeared (240 msec); (3) a 1,760 -msec response period was given; and (4) an intertrial inter- val occurred ( $750 \mathrm{msec})$. Thus, on each trial, the participant had $2,000 \mathrm{msec}$ in which to respond from the onset of the target display. If no response was made, the next trial began. The participants received no feedback regarding accuracy. The participants were instructed to focus their attention on the fixation display and then to select the center letter in the target display and to ignore the flankers. The participants were instructed to respond as quickly and accurately as possible. Following the practice trials for each assigned similarity $X$ interletter distance block, the 72 experimental trials were administered.

\section{Results}

In analyzing the reaction time data, all the trials on which the participant responded prior to target presentation or failed to respond within the time-out period were eliminated (.001). In addition, all trials on which an error occurred were eliminated. From the remaining correct observations (.96), response latencies greater than three $S D$ s from the overall mean for each subject/condition were deleted as outliers. This resulted in the loss of $0.9 \%$ of the observations. The significance level for all the tests was set at $p<.05$, two-tailed.

\section{Response Latency}

Tables 1 and 2 show, for each condition, the mean response latencies and the facilitation (congruent minus neutral) and interference (incongruent minus neutral) effects, respectively. First, note that overall response latencies are, in general, slower for the similar flanker condition ( $513 \mathrm{msec})$ than for the dissimilar flanker condition (476 msec). Second, a facilitation effect is present and appears larger for the dissimilar flanker condition than for the similar flanker condition. Third, the interference effect across both similarity conditions is larger in the narrow interletter distance condition than in the wide interletter distance condition. Fourth, the interference effect is larger in the dissimilar flanker condition than in the similar flanker condition, but only with a narrow interletter distance.

These observations were supported by an overall $2 \times$ $2 \times 3$ repeated measures analysis of variance (ANOVA), with similarity (dissimilar, similar), interletter distance (narrow, wide), and flanker compatibility (congruent, incongruent, neutral) as within-subjects factors. There were main effects of similarity, $\left[F(1,14)=36.82, M S_{\mathrm{e}}=\right.$

Table 1

Mean Choice Response Latencies (in Milliseconds) and Percent Error as a Function of Flanker Similarity and Interletter Distance in Experiment 1

\begin{tabular}{|c|c|c|c|c|c|c|c|c|c|c|c|c|}
\hline & \multicolumn{6}{|c|}{ Dissimilar } & \multicolumn{6}{|c|}{ Similar } \\
\hline & \multicolumn{3}{|c|}{ Narrow } & \multicolumn{3}{|c|}{ Wide } & \multicolumn{3}{|c|}{ Narrow } & \multicolumn{3}{|c|}{ Wide } \\
\hline & $\mathrm{C}$ & $\mathrm{N}$ & I & $\mathrm{C}$ & $\mathrm{N}$ & I & $\mathrm{C}$ & $\mathrm{N}$ & I & $\mathrm{C}$ & $\mathrm{N}$ & I \\
\hline \multicolumn{13}{|c|}{ Response time } \\
\hline$M$ & 464 & 482 & 541 & 437 & 460 & 475 & 499 & 513 & 554 & 496 & 500 & 514 \\
\hline$S E$ & 21 & 19 & 21 & 18 & 16 & 14 & 17 & 17 & 17 & 20 & 20 & 17 \\
\hline \multicolumn{13}{|c|}{ Percentage error } \\
\hline$M$ & .006 & .017 & .056 & .014 & .031 & .033 & .011 & .019 & .042 & .008 & .031 & .044 \\
\hline$S E$ & .004 & .007 & .014 & .009 & .008 & .009 & .005 & .007 & .008 & .004 & .010 & .010 \\
\hline
\end{tabular}


Table 2

Mean Choice Response Latency Differences for the Facilitation (Congruent Minus Neutral) and Interference Effects (Incongruent Minus Neutral) as a Function of Flanker Similarity and Interletter Distance in Experiment 1

\begin{tabular}{|c|c|c|c|c|c|c|c|c|}
\hline & \multicolumn{4}{|c|}{ Dissimilar } & \multicolumn{4}{|c|}{ Similar } \\
\hline & \multicolumn{2}{|c|}{ Narrow } & \multicolumn{2}{|c|}{ Wide } & \multicolumn{2}{|c|}{ Narrow } & \multicolumn{2}{|c|}{ Wide } \\
\hline & Facil & Interf & Facil & Interf & Facil & Interf & Facil & Interf \\
\hline$M$ & -18 & 59 & -23 & 15 & -14 & 40 & -4 & 15 \\
\hline$S E$ & 7 & 6 & 7 & 5 & 6 & 7 & 5 & 7 \\
\hline
\end{tabular}

$1,614, p<.0001]$, which indicated that overall response times in the similar flanker condition were slower than in the dissimilar flanker condition, and interletter distance, $\left[F(1,14)=30.32, M S_{\mathrm{e}}=1,217, p<.0001\right]$, which indicated that overall response times were slower in the narrow distance condition than in the wide distance condition. There was also a reliable effect of flanker $[F(2,28)=$ $\left.74.83, M S_{\mathrm{e}}=465, p<.0001\right]$; a post hoc test showed that response times increased reliably from the congruent to the neutral to the incongruent condition $(p \mathrm{~s}<.0008)$. The similarity $\times$ flanker interaction $\left[F(2,28)=7.28, M S_{\mathrm{e}}\right.$ $=235, p<.003]$, and the interletter distance $\times$ flanker interaction were both reliable and will be addressed further below within the context of examining the facilitation and interference effects. Although the similarity $x$ interletter distance $\times$ flanker interaction was not reliable here in the overall analysis $\left[F(2,28)=1.52, M S_{\mathrm{e}}=225\right.$, $p=.24]$, as will be seen, this can be attributed to the influence of the congruent condition. None of the other interactions were reliable (all $p \mathrm{~s}>.12$ ).

Facilitation effects. To examine the facilitation effects, difference scores were computed (congruent minus neutral) and entered into a $2 \times 2$ repeated measures ANOVA, with similarity (dissimilar, similar) and interletter distance (narrow, wide) as within-subjects factors. The results showed a marginal effect of similarity $[F(1,14)$ $\left.=4.07, M S_{\mathrm{e}}=489, p=.06\right]$, which suggested that the magnitude of the facilitation effect was larger in the dissimilar than in the similar condition. None of the other effects was reliable ( $p s>.28)$.

Interference effects. To examine the interference effects, difference scores were computed (incongruent minus neutral) and entered into an ANOVA identical to that described for the facilitation effects. The results yielded a marginal effect of similarity $[F(2,45)=4.30$, $\left.M S_{\mathrm{e}}=336, p=.06\right]$, which suggested that the interference effect was larger for the dissimilar than for the similar condition, a reliable effect of interletter distance, which showed that the interference effect was larger in the narrow than in the wide condition, and a similarity $X$ interletter distance interaction $\left[F(1,14)=6.54, M S_{\mathrm{e}}=\right.$ $185, p<.02]$. Post hoc testing revealed that the interference effect was reliably larger in the dissimilar condition than in the similar condition, given a narrow interletter spacing $(p<.002)$, but not a wide interletter spacing $(p=.87)$.

\section{Error Analyses}

Table 1 shows the mean percentage error rate for each condition. As can be seen, the error rates increase across the congruent, neutral, and incongruent conditions. However, there appears to be no interaction of either targetflanker similarity or interletter distance with the flanker compatibility effects.

These observations were supported by an overall $2 \times$ $2 \times 3$ repeated measures ANOVA, with similarity (dissimilar, similar), interletter distance (narrow, wide), and flanker compatibility (congruent, incongruent, neutral) as within-subjects factors. The results yielded only a main effect of flanker compatibility $[F(2,28)=19.03$, $\left.M S_{\mathrm{e}}=0.51, p<.0001\right]$. Post hoc testing revealed that the error rates increased reliably from the congruent to the neutral to the incongruent condition $(p<.01$, both cases).

\section{Discussion}

The results of Experiment 1 showed that participants were slower to identify similar than dissimilar targets and slower to identify targets surrounded by near, rather than far, flankers. However, these two factors did not interact in the overall reaction times. The overall slowing of reaction times to the similar targets, which also was observed by Zeef et al. (1996), appears to be due to a confusion over which target is present, independent of any slowing owing to lateral inhibitory connections between similar target and flanker features (Bjork \& Murray, 1977; Estes, 1982; LaBerge \& Brown, 1989). Although there was an overall reliable facilitation effect, the confusion regarding the identity of similar targets also may have contributed to the trend toward a larger effect for dissimilar than for similar targets. That is, even though the target and flankers were identical in the congruent conditions, the participants appear to have benefited more when the context of the experiment (i.e., dissimilar targets) provided a clear distinction between targets. This notion will be addressed further below. The facilitation effect, however, did not interact reliably with interletter distance.

In contrast, there was a reliable similarity $\times$ interletter distance interaction in the interference effect. When the target and flankers were separated by a wide interletter distance, there was no difference in the magnitude of the interference effect between the dissimilar and the 
similar conditions. However, when the target and flankers were in close proximity, the interference effect was reliably larger in the dissimilar than in the similar condition. These results replicate the well known finding that increasing the interletter distance reduces the magnitude of the interference effect (see, e.g., B. A. Eriksen \& C. W. Eriksen, 1974; Yantis \& Johnston, 1990). However, the novel finding of greater interference for dissimilar than for similar targets at the narrow interletter distance suggests that Zeef et al.'s (1996) failure to observe an effect of similarity on the magnitude of the interference effect was due, in part, to their use of a wide $\left(\geq 0.47^{\circ}\right)$ interletter distance.

At the outset, I hypothesized that enhancing the operation of the spatial filter during early perceptual processing might function to reduce competition, by either reducing the processing of the flanker identity (LaBerge \& Brown, 1989; LaBerge et al., 1991) or allowing the incongruent response channel's activation to decay (Coles et al., 1992). However, a closer inspection of the data suggests that this may not have occurred. If increasing target-flanker similarity and narrowing interletter distance are more likely to enhance the function of the spatial filter, response times to similar targets should be faster than response times to dissimilar targets in the incongruent condition, owing to a reduction in response competition, but not in the neutral condition, given that their target-flanker feature similarity was equated. To address this question, differences scores were calculated by subtracting the mean response time to dissimilar targets from the mean response time to similar targets. This showed that the magnitude of the difference was positive and larger in the neutral than in the incongruent condition with narrow interletter spacing (neutral - mean = $32 \mathrm{msec}, S E=10$; incongruent - mean $=13 \mathrm{msec}$, $S E=9$ ), but not with wide interletter spacing (neutral mean $=40 \mathrm{msec}, S E=11$; incongruent - mean $=$ $39 \mathrm{msec}, S E=11$ ). These data suggest that the decrease in the magnitude of interference cannot be accounted for by increased spatial filtering.

So how can we account for these results? Several studies using both alphanumeric and nonalphanumeric characters have shown that the perceptual processing of global shape or color information (in isolation or in conjunction with color/shape) within the same hierarchical level is available prior to local shape information (e.g., C. W. Eriksen \& Schultz, 1979; Miller, 1982; Miller \& Hackley, 1992; Navon, 1977; Smid, Bocker, van Touw, Mulder, \& Brunia, 1996; Smid \& Heinze, 1997; but see Ridderinkhof \& van der Molen, 1995; Smid, Mulder, Mulder, \& Brands, 1992), and depending on the participant's strategy for responding (i.e., whether it yields performance benefits), the global information may or may not be used to activate a response before the local shape elements are identified (Coles, De Jong, Gehring, \& Gratton, 1991; Smid et al., 1996).

As with the trend toward greater facilitation for the dissimilar than for the similar targets, the analysis of the interference data also suggests that it is the difference in target similarity between the two response sets that is modulating the magnitude of the interference effect. Specifically, there appear to be two sources for the effect of target similarity. First, the targets in the dissimilar response set (YQ) can be differentiated at a global level, whereas the targets within the similar response set can only be differentiated at a local level (VY), given their global similarity (i.e., the downpointing arrowhead; Pomerantz, 1983; Smid \& Heinze, 1997). The data are consistent with the notion that target selection (i.e., stimulusresponse translation) is overall faster for the dissimilar than for the similar targets because correct selection of a dissimilar target is possible on the basis of the early availability of global shape information, whereas correct selection of a similar target must await the availability of local shape information. Moreover, Smid et al. (1991) have shown that if, for example, $Q$ is assigned as a target in a choice task, presentation of a nontarget letter, such as $G$, that shares a global feature with the target produced an initial activation of the target response channel. This suggests that, in the present task, the longer response times to similar than to dissimilar targets in the neutral condition also may be due, in part, to the shared global feature activating both responses. ${ }^{1}$ Second, an inspection of the data showed that the magnitude of the difference in response times between similar and dissimilar targets was larger in the neutral than in the incongruent condition, but only at a narrow interletter distance. Moreover, at the narrow interletter distance, the response times to dissimilar and similar targets were of a similar magnitude in the incongruent condition. This suggests that the dissimilar flankers were activating their response channels to the same degree as were similar flankers. Thus, even though selection can occur faster for dissimilar than for similar targets, the presence of strong response competition at the narrow interletter distance appears to delay response selection sufficiently to reduce the benefit. In contrast, when the response competition is reduced by increasing interletter distance, the benefit of selection on the basis of global shape information appears to emerge. In this regard, it should be noted that blocking, rather than randomly varying interletter distance, may have contributed to this reduction at the wide interletter distance by minimizing the influence of flanker processing. Nevertheless, these results contrast with those of C. W. Eriksen and B. A. Eriksen (1979), who found essentially no effect of similarity within neutral or incongruent conditions. However, this is not suprising, given that the targets within their dissimilar (HK) and similar (SC) response sets can both be differentiated at a global feature level.

\section{EXPERIMENT 2}

The purpose of Experiment 2 was twofold. First, I wanted to replicate the finding that the magnitude of the interference effect decreases with increases in target re- 
sponse set similarity. Second, in Experiment 2, I examined how the perceptual and response activation processes underlying this reduction may be influenced by aging.

With regard to age-related changes in visual sensory processing, the literature shows that there is an agerelated decrement in the ability to extract parafoveal information efficiently, even when optical techniques are employed to equate acuity across young and old adults (e.g., Sekular \& Ball, 1986). This has been shown to protect older adults from the influence of distractors presented at wide interletter distances, especially when letter size is small (e.g., Cerella, 1985; Hartley \& McKenzie, 1991). Within foveal view, evidence from letter- and shapematching tasks has shown consistent age-related decrements in perceptual processing (Allen, Weber, \& Madden, 1994; Allen, Weber, \& May, 1993; Krueger \& Allen, 1987; see also Madden, Pierce, \& Allen, 1993). For example, Allen et al. (1994) found a larger falsedifferent effect for errors in which older adults were more likely to say that two identical letters are different. They attributed this to an age-related increase in what they termed internal perceptual noise, which functions to distort the visual features composing the letter identities.

With regard to response activation, the literature is equivocal, because some studies have provided evidence for an age-related increase in the interference effect (e.g., Cerella, 1985; Zeef \& Kok, 1993; Zeef et al., 1996), whereas others have not (e.g., Faust, Balota, \& Duchek, 1995; Kramer, Humphrey, Larish, \& Logan, 1994; Plude \& Hoyer, 1986; Wright \& Elias, 1979). The majority of studies failing to find an age-related decrement in the interference effect have used tasks in which the flankers were visually dissimilar to the target (e.g., KHK; Faust et al., 1995; Kramer et al., 1994; Wright \& Elias, 1979). In contrast, Zeef and Kok provided evidence in support of an age-related increase in interference, given flankers that were visually similar to the target (e.g., HHNHH). In an attempt to determine whether target-flanker similarity might account for the difference across studies, Zeef et al. used a within-subjects design to determine whether increasing target-flanker similarity would produce an age-related increase in the interference effect. The results disconfirmed this hypothesis, since the results showed an age-related increase in the interference effect that was of a similar magnitude for both visually similar and visually dissimilar flankers. On the one hand, as was suggested by Zeef and Kok (1993), these results do not support the notion that age-related increases in interference are perceptually based. Rather, the results point to an age-related increase in response competition. On the other hand, their finding of an age-related increase in the interference effect with dissimilar target and flankers is at odds with the absence of this effect in the majority of previous studies (Faust et al., 1995; Kramer et al., 1994; Plude \& Hoyer, 1986). One reason for this may be that Zeef et al., as well as other studies showing an age-related increase in the interference effect even with dis- similar targets and flankers (e.g., Cerella, 1985), did not account for the generalized slowing associated with increasing age, which is known to produce larger effect sizes in older adults than in young adults (see, e.g., Cerella \& Hale, 1994; Myerson, Hale, Wagstaff, Poon, \& Smith, 1990).

Therefore, in light of these equivocal findings, in Experiment 2 the question of whether an age-related decrement in selection exists and, to the extent that it does, whether it is mediated by an age-related decrement in perceptual processing or an age-related increase in response competition was examined. To evaluate the generality of the influence of target similarity on the magnitude of the interference effect, and in an attempt to replicate a recent study by Faust et al. (1995) showing no age-related decline in the interference effect with a simultaneous target display, a stimulus set different from that in Experiment 1 was employed for the dissimilar condition. In contrast to Zeef et al. (1996) and the majority of previous studies, Experiment 2 included not only young and young-old adults (55-79 years of age), but also old-old adults ( $79+$ years of age), to examine the influence of advanced aging. In addition, on the basis of the results of Experiment 1, Experiment 2 employed a small interletter distance $\left(0.09^{\circ}\right)$ between target and flankers, as well as a short display duration $(240 \mathrm{msec})$. The use of a small interletter distance should reduce the likelihood of an age-related decrease in the ability to extract information from the flankers (Cerella, 1985; Hartley \& McKenzie, 1991). Along these same lines, it is important to note that the $240-\mathrm{msec}$ display duration used in the present study is longer than that used by Cerella (Experiment 3; $200 \mathrm{msec}$ ), who reported an agerelated increase in interference with a $0.7^{\circ}$ interletter distance. Finally, Experiment 2 also will employ analyses that take into account overall age-related speed differences.

On the basis of the results of Experiment 1, the interference effect should be reliably larger in the dissimilar than in the similar condition. However, whether age interacts with either of these effects is an empirical question. To the extent that an interaction is obtained, the pattern of effects within the incongruent and neutral conditions should reveal the underlying cause for any agerelated decrements. If there is an age-related decrement in the perceptual processing of global or local shape information, but no age-related increase in response competition, there should be an age-related increase in response times to dissimilar and similar targets in the neutral condition, but not in the incongruent condition. Moreover, an age-related increase in response times to similar, but not to dissimilar, targets within the neutral condition would suggest a specific reduction in the availability of local, but not global, information. The absence of a difference in the incongruent condition is based on the results of Experiment 1, which suggest that strong response competition reduces the benefit from speeded perceptual processing. In contrast, if there is no age- 
related decrement in the availability of global (dissimilar targets) or local (similar targets) shape information, but there is an age-related increase in response competition, there should be a disproportionate age-related increase in response times to targets in the incongruent condition, but not in the neutral condition.

On the basis of Experiment 1, the results of Experiment 2 may yield a larger facilitation effect for dissimilar than for similar targets. Although previous studies have shown no age-related decrement in facilitation (e.g., Balota \& Duchek, 1991; Spieler, Balota, \& Faust, 1996; Sullivan \& Faust, 1993), the magnitude of the facilitation effect may be larger in the similar than in the dissimilar condition for the older adults, owing to slower response times in the similar, neutral condition.

Experiment 2 also included narrow and wide focusof-attention conditions, since LaBerge et al. (1991) have provided evidence that the spatial filter, under top-down control, can function to narrow the focus of attention around the location of the target and to reduce response competition. In the narrow focus condition, the participants were first required to fixate their attention on a single fixation cross and then to process a single letter that appeared briefly prior to the target display. In the wide focus condition, the participants were first required to fixate their attention on a fixation cross flanked by two filled circles and then to process a three-letter word that appeared briefly prior to the target display. This procedure is similar to that of LaBerge and his colleagues (LaBerge \& Brown, 1989; LaBerge et al., 1991). However, to simplify the task, no catch trials were included for the reading of the single letters and words. Although the absence of catch trials may allow the participants to avoid reading the words, according to LaBerge and Brown this is unlikely, because words are automatically processed as wholes. The attentional focus conditions were included for two reasons. The first was to examine whether the older adults could adjust and maintain their focus of attention. Previous studies have provided mixed results. For example, in visual search tasks, young-old adults appear to be able to use a cue to adjust their focus of attention to identify a target, (Madden, 1992; Madden, Connelly, \& Pierce, 1994), whereas old-old adults ( $>75$ years of age) show an age-related decrement (Greenwood, Parasuraman, \& Alexander, 1997). In contrast, Hartley and McKenzie (1991) have shown that youngold adults benefited more from a narrow than from a wide focus of attention in a target detection task. Second, a wide focus of attention was included, in an attempt to create a more sensitive measure of any agerelated decrement in perceptual processing, independent of changes in attention (Hartley \& McKenzie, 1991). In sum, to the extent that participants adjust their focus of attention according to the task demands, a narrow focus of attention should produce a smaller interference effect than does a wide focus of attention (LaBerge et al., 1991; Paquet \& Lortie, 1990).

\section{Method}

\section{Participants}

Seventeen young adults (mean age $=22.47$ years, $S D=4.38$ ), 15 young-old adults (mean age $=67.2$ years, $S D=4.52$ ), and 16 old-old adults (mean age $=86.56$ years, $S D=4.18$ ) participated in the experiment. The mean years of education were $14.4(S D=$ $2.67)$ for the young adults, $15.2(S D=1.93)$ for the young-old adults, and $15.5(S D=4.18)$ for the old-old adults. The mean years of education did not differ reliably between the groups $[F(2,45)=$ $\left.0.72, M S_{\mathrm{e}}=7.30, p=.49\right]$. The young adults were recruited from Portland State University and Oregon Health Sciences University. The young-old adults were recruited from the Portland community, and the old-old adults were recruited from a pool of optimally healthy old-old adults who were followed yearly by the Oregon Brain Aging Study at Oregon Health Sciences University.

The mean normal or corrected visual acuities were 20/24.7 $(S D=7.8)$ for the young adults, $20 / 39(S D=5.41)$ for the youngold adults, and $20 / 32.5(S D=10.17)$ for the old-old adults. Both groups of old adults were screened for depression with the Geriatric Depression Scale and for any other mental disorders that could affect cognitive function. The old adults were administered the Mini-Mental Status Examination (M. F. Folstein, S. E. Folstein, \& $\mathrm{McHugh}, 1975$ ). The mean score for the young-old adults was 29.5 $(S D=0.97)$, and the mean score for the old-old adults was 28.88 $(S D=1.15)$. Although the mean scores of young-old and old-old adults were reliably different from each other $[F(1,29)=5.12$, $\left.M S_{\mathrm{e}}=0.93, p<.03\right]$, both groups scored within the normal range.

\section{Stimuli}

The stimuli consisted of uppercase white characters presented on a black screen in Geneva 18 bold font. The viewing distance as well as the size and spacing of the stimuli at the narrow interletter distance were the same as those in Experiment 1. The visual similarity of the target and flanker letters in the dissimilar and similar flanker conditions was based on the number of shared features, in accordance with the feature set provided by Keren and Baggen (1981). The target letters in the similar flanker condition (V, Y) shared twice as many features as the target letters in the dissimilar flanker condition $(E, H)$. The average number of shared features between the targets and the flankers in the neutral conditions of the similar (YZ, VZ) and dissimilar (ES, HS) flanker conditions was two. Letters and words in the narrow and wide focus conditions were selected on the basis of their dissimilarity to all the letters appearing in the target display. The letters appearing in the narrow focus condition were $\mathrm{D}, \mathrm{C}, \mathrm{G}, \mathrm{J}$, and $\mathrm{O}$, and the words appearing in the wide focus condition were DOG, TOP, PIT, KIT, and.LOT.

\section{Design}

The design consisted of the between-subjects factor of group (young adults, young-old adults, and old-old adults) and the withinsubjects factors of flanker similarity (similar, dissimilar), attentional focus (narrow, wide), and response compatibility (congruent, incongruent, neutral). The flanker similarity condition was blocked and counterbalanced across participants, so that half of the experimental trials required a response to targets from the similar condition $(\mathrm{Y}, \mathrm{V})$ and the other half required a response to targets from the dissimilar condition $(\mathrm{E}, \mathrm{H})$. The attentional focus condition also was blocked and counterbalanced across participants within each flanker similarity condition. Following LaBerge and Brown (1989), the focus conditions were blocked, rather than intermixed, in an at- 
tempt to facilitate a consistent spatial focus of attention on the targetflanker arrays. Thus, there were four possible orders for presentation of the similarity and focus conditions. Each of the similarity $x$ focus blocks contained 24 congruent trials, 24 incongruent trials, and 24 neutral trials, for a total of 288 experimental trials. In the congruent condition, flanker letters were identical to the central target letter (i.e., similar, YYY, VVV; dissimilar, EEE, HHH). In the incongruent condition, the flankers letters competed with the target letter for response selection (i.e., similar, VYV, YVY; dissimilar, $\mathrm{HEH}, \mathrm{EHE}$ ). In the neutral condition, flankers were not associated with a response (i.e., similar, ZYZ, ZVZ; dissimilar, SES, SHS).

\section{Apparatus}

The apparatus was the same as that in Experiment 1.

\section{Procedure}

The participants were tested individually in a dimly lit room. First, they were given practice in mapping the target letters of the currently assigned similarity condition (i.e., $\mathrm{E}, \mathrm{H}$ or $\mathrm{Y}, \mathrm{V}$ ) to their respective response keys. This was done in the same manner as that in Experiment 1 . The experimenter then presented a minimum of 18 practice trials composed of 3 trials in each of the two focus $\times$ three flanker conditions. Some participants required additional practice and, therefore, were presented with an additional 18 practice trials. On each trial, the participant saw the following series of events centered in the screen: (1) In the narrow focus condition, a fixation cross appeared, and in the wide focus condition, a fixation cross between two black circles appeared $(1,000 \mathrm{msec}) ;(2)$ one of the five focus letters was randomly selected and appeared in the narrow focus condition, or one of the five focus words was randomly selected and appeared in the wide focus condition $(165 \mathrm{msec})$; (3) one of the six possible target displays for the similar or the dissimilar condition was randomly selected and appeared (240 msec); (4) a $1,760 \mathrm{msec}$ response period was given; and (5) an intertrial interval occurred (750 msec). Thus, on each trial, the participant had $2,000 \mathrm{msec}$ in which to respond from the onset of the target display. If no response was made, the next trial began. The participants received no feedback regarding accuracy. The participants were instructed to focus their attention on the fixation display, to covertly read the letter or word presented in the focus display, and then to select the center letter in the target display and ignore the flankers. The participants were instructed to respond as quickly and accurately as possible. Following the practice trials for each assigned similarity $\times$ focus block, the 72 experimental trials were administered.

\section{Results}

In the analysis of the response times, all the trials on which the participant responded prior to target presenta- tion or failed to respond within the time-out period were eliminated (mean: young, .003; young-old, .006: old-old, $.008)$. In addition, all the trials on which an error occurred were eliminated. From the remaining correct observations (young, .96; young-old, .97: old-old, .96), response latencies greater than three $S D$ s from the overall mean for each subject/condition were deleted as outliers. This resulted in the loss of $1 \%$ of the observations for the young adults, $0.9 \%$ for young-old adults, and $1.2 \%$ for the old-old adults. The significance level for all the tests was set at $p<.05$, two-tailed.

\section{Response Latency}

Tables 3 and 4 show, for each group and condition, the mean response latencies and the facilitation (congruent minus neutral) and interference (incongruent minus neutral) effects, respectively. First, note that overall response latencies increased as the mean age increased (young = $520 \mathrm{msec}$; young-old $=653 \mathrm{msec}$; old-old $=759 \mathrm{msec}$ ). Second, response latencies are, in general, slower for the similar flanker condition $(666 \mathrm{msec})$ than for the dissimilar flanker condition ( $617 \mathrm{msec})$ and, in general, faster in the narrow focus condition $(619 \mathrm{msec})$ than in the wide focus condition $(663 \mathrm{msec})$. Third, a similar facilitation effect is present across the three age groups. In contrast, the interference effect is larger for the dissimilar flanker condition than for the similar flanker condition for the young and young-old adults. However, for the old-old adults, although a similar pattern can be seen, an interference effect is present for the dissimilar flanker condition, but not for the similar flanker condition.

These observations were supported by an overall $3 \times 2$ $\times 2 \times 3$ mixed factor ANOVA, with age (young, youngold, old-old) as a between-subjects factor and similarity (dissimilar, similar), focus (narrow, wide), and flanker (congruent, incongruent, neutral) as within-subjects factors. There were main effects of age $[F(2,45)=30.04$, $\left.M S_{\mathrm{e}}=94,842, p<.0001\right]$, which indicated that response times increased with age, similarity $[F(1,45)=$ $\left.18.73, M S_{\mathrm{e}}=18,471, p<.0001\right]$, which indicated that overall response times in the similar flanker condition were slower than those in the dissimilar flanker condi-

Table 3

Mean Choice Response Latencies (in Milliseconds) as a Function of Group, Flanker Similarity, Attentional Focus, and Response Compatibility in Experiment 2

\begin{tabular}{|c|c|c|c|c|c|c|c|c|c|c|c|c|}
\hline & \multicolumn{6}{|c|}{ Dissimilar } & \multicolumn{6}{|c|}{ Similar } \\
\hline & \multicolumn{3}{|c|}{ Narrow } & \multicolumn{3}{|c|}{ Wide } & \multicolumn{3}{|c|}{ Narrow } & \multicolumn{3}{|c|}{ Wide } \\
\hline & $\mathrm{C}$ & $\mathrm{N}$ & I & $\mathrm{C}$ & $\mathrm{N}$ & $\mathbf{I}$ & $\mathrm{C}$ & $\mathrm{N}$ & I & $\mathrm{C}$ & $\mathrm{N}$ & I \\
\hline \multicolumn{13}{|c|}{ Young } \\
\hline$M$ & 474 & 485 & 523 & 505 & 508 & 550 & 504 & 520 & 539 & 528 & 539 & 559 \\
\hline$S E$ & 15 & 19 & 17 & 18 & 18 & 17 & 12 & 13 & 11 & 16 & 16 & 17 \\
\hline \multicolumn{13}{|c|}{ Young-old } \\
\hline$M$ & 570 & 580 & 615 & 658 & 682 & 714 & 638 & 645 & 676 & 674 & 681 & 707 \\
\hline$S E$ & 18 & 18 & 23 & 39 & 42 & 40 & 19 & 19 & 20 & 23 & 24 & 29 \\
\hline \multicolumn{13}{|c|}{ Old-old } \\
\hline$M$ & 688 & 683 & 715 & 707 & 718 & 772 & 759 & 791 & 778 & 825 & 835 & 834 \\
\hline$S E$ & 39 & 35 & 30 & 24 & 22 & 21 & 161 & 44 & 31 & 41 & 43 & 35 \\
\hline
\end{tabular}

Note- $C$, congruent; $N$, neutral; $I$, incongruent. 
Table 4

Mean Choice Response Latency Differences for the Facilitation (Facil, Congruent Minus Neutral) and Interference (Interf, Incongruent Minus Neutral) Effects as a Function of Group, Flanker Similarity, and Attentional Focus in Experiment 2

\begin{tabular}{|c|c|c|c|c|c|c|c|c|}
\hline & \multicolumn{4}{|c|}{ Dissimilar } & \multicolumn{4}{|c|}{ Similar } \\
\hline & \multicolumn{2}{|c|}{ Narrow } & \multicolumn{2}{|c|}{ Wide } & \multicolumn{2}{|c|}{ Narrow } & \multicolumn{2}{|c|}{ Wide } \\
\hline & Facil & Interf & Facil & Interf & Facil & Interf & Facil & Interf \\
\hline \multicolumn{9}{|c|}{ Young } \\
\hline$M$ & -11 & 38 & -2 & 42 & -16 & 19 & -11 & 20 \\
\hline$S E$ & 7 & 9 & 6 & 4 & 5 & 6 & 8 & 5 \\
\hline \multicolumn{9}{|c|}{ Young-old } \\
\hline$M$ & -11 & 35 & -24 & 32 & -7 & 30 & -7 & 25 \\
\hline$S E$ & 7 & 8 & 7 & 9 & 8 & 8 & 8 & 10 \\
\hline \multicolumn{9}{|c|}{ Old-old } \\
\hline$M$ & 5 & 32 & -10 & 54 & -32 & -13 & -10 & -0.72 \\
\hline$S E$ & 13 & 7 & -11 & 9 & -11 & -19 & -16 & -11 \\
\hline
\end{tabular}

tion, and focus $\left[F(1,45)=30.95, M S_{\mathrm{e}}=9,370, p<\right.$ $.0001]$, which indicated that overall response times were slower in the wide focus condition than in the narrow focus condition. There was also a reliable effect of flanker $\left[F(2,90)=79.57, M S_{\mathrm{e}}=886, p<.0001\right]$. StudentNewman-Keuls post hoc tests showed that response times increased reliably from the congruent to the neutral condition and from the neutral to the incongruent condition $(p<.01$, in both cases $)$. The age $\times$ similarity interaction was reliable $\left[F(2,45)=3.30, M S_{\mathrm{e}}=18,471\right.$, $p<.046$ ], which suggested that the magnitude of the difference in overall response latencies between the dissimilar flanker condition and the similar flanker condition was larger for the old-old adults than for either the young or the young-old adults. However, a similar analysis revealed that this interaction was not reliable after accounting for differences in overall speed (i.e., dependent variable $=$ each condition mean/overall mean for each participant) between the three groups $[F(2,45)=1.85$,
$M S_{\mathrm{e}}=0.033, p=.17$; Cerella \& Hale, 1994; Myerson et al., 1990; Spieler et al., 1996]. This suggests that the slower response times of the old-old adults were inflating the differences between conditions. The similarity $x$ flanker $\left[F(2,72)=12.90, M S_{\mathrm{e}}=704, p<.0001\right]$, and age $\times$ similarity $\times$ flanker $\left[F(4,72)=3.51, M S_{\mathrm{e}}=704\right.$, $p<.01]$, interactions were both reliable and will be addressed further below within the context of examining the facilitation and interference effects. None of the other interactions involving group, similarity, focus, and flanker were reliable (all $p \mathrm{~s}>.12$ ).

Facilitation effects. As a means of accounting for the influence of overall speed, each participant's condition mean was divided by his or her overall mean and entered into a $3 \times 2 \times 2 \times 2$ mixed factor ANOVA with age as a between-subjects factor (young, young-old, old-old) and similarity (dissimilar, similar), focus (narrow, wide), and flanker (congruent, neutral) as within-subjects factors. The proportional scores for the dissimilar and sim-

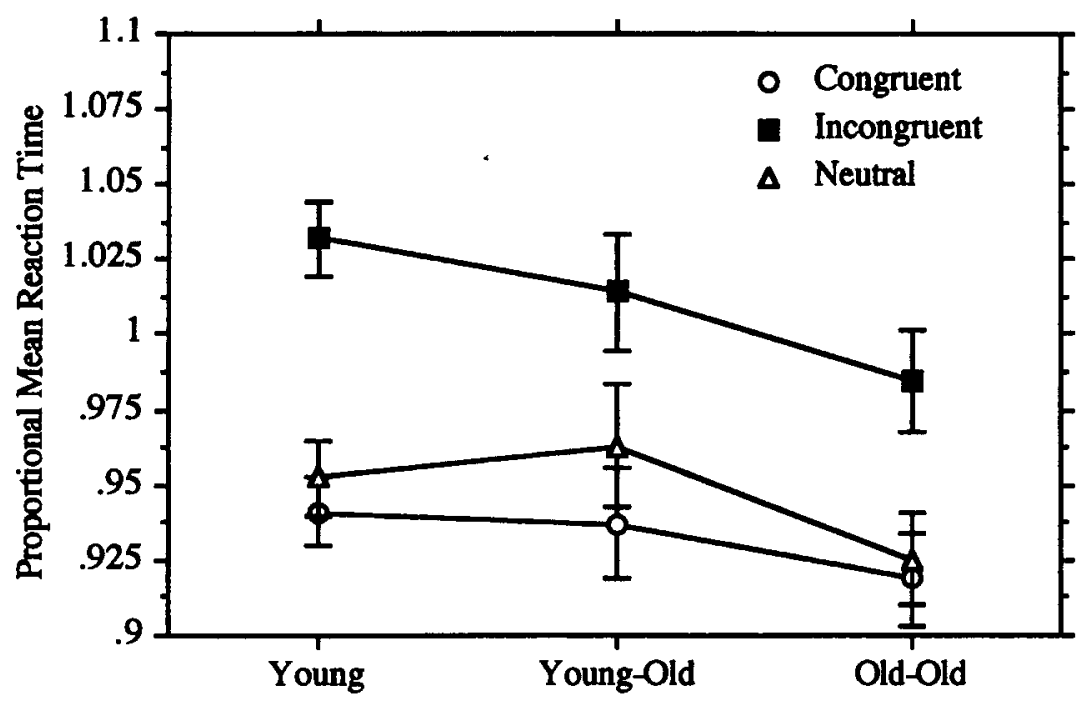

Figure 1. Mean proportional response latencies for the dissimilar condition as a function of age and flanker compatibility in Experiment 2. 


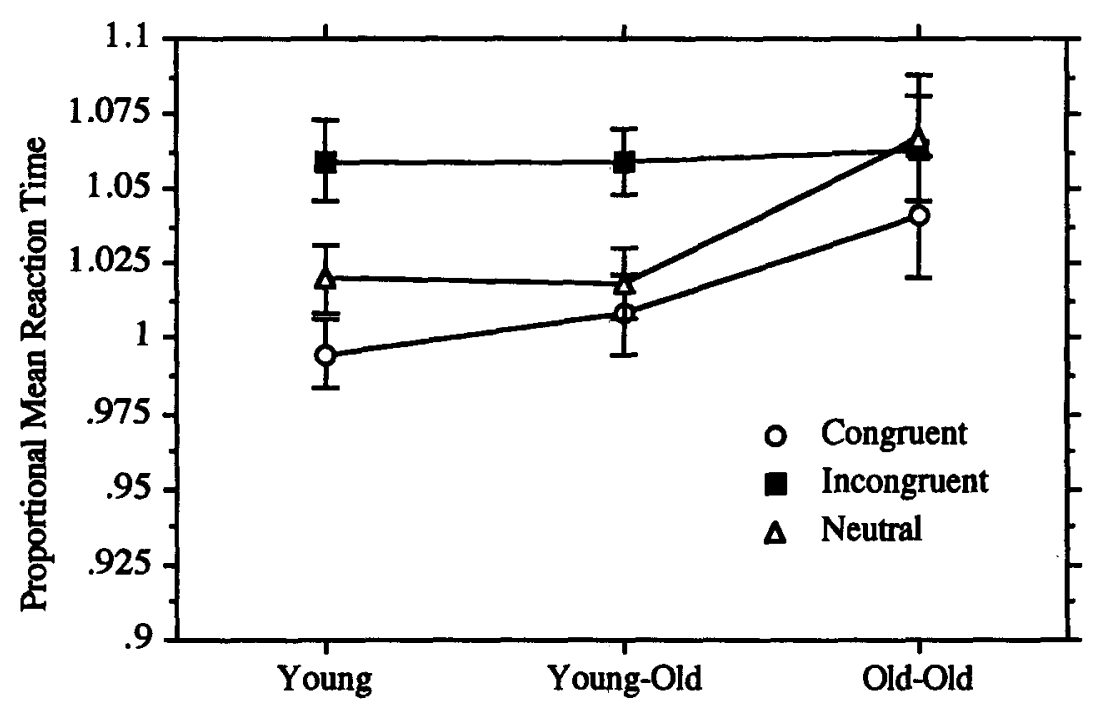

Figure 2. Mean proportional response latencies for the similar condition as a function of age and flanker compatibility in Experiment 2.

ilar condition are shown in Figures 1 and 2 . The results yielded only a main effect of flanker $[F(1,45)=21.86$, $\left.M S_{\mathrm{e}}=0.001, p<.0001\right]$, which showed that responses were faster in the congruent than in the neutral condition. None of the other interactions was reliable (all $p \mathrm{~s}>$ $.10)$. In sum, the analysis of flanker effects yielded reliable effect scores that were similar in magnitude across the three groups.

Interference effects. As above, proportional scores were computed as a means for accounting for overall speed differences between groups and entered into an ANOVA identical to that described for the flanker facilitation effect, with the exception that the flanker factor contained scores for the incongruent and neutral conditions (see Figures 1 and 2). The results yielded a similarity $\times$ flanker interaction $\left[F(1,45)=24.70, M S_{\mathrm{e}}=\right.$ $0.003, p<.0001]$, which showed that the magnitude of the interference effect was reliably larger in the dissimi$\operatorname{lar}(M=.064, S D=.005)$ than in the similar condition $(M=.026, S D=.006)$ and that there was a reliable age $\times$ similarity $\times$ flanker interaction $\left[F(2,45)=3.98, M S_{\mathrm{e}}=\right.$ $0.001, p<.025]$. To examine this interaction for the dissimilar and similar conditions, two mixed factor ANOVAs were calculated, with age as a between-subjects factor (young, young-old, old-old) and similarity (dissimilar, similar) and flanker (incongruent, neutral) as withinsubjects factors. For the dissimilar flanker condition, there was no reliable age $\times$ flanker interaction $[F(2,45)=$ $\left.2.27, M S_{\mathrm{e}}=0.002, p=.12\right]$. The estimated power to detect an age-related difference in the interference effect was .57. In contrast, for the similar flanker condition, the results yielded a reliable age $\times$ flanker interaction $\left[F(2,45)=5.71, M S_{\mathrm{e}}=0.002, p<.006\right]$. The estimated power to detect an age-related difference in the interference effect was .75 . A post hoc Student-Newman-Keuls test showed that the magnitude of the interference effect (incongruent minus neutral) for the old-old adults was reliably smaller than for either the young or the youngold adults $(p<.05)$. None of the other interactions was reliable (all $p s>.15$ ).

Table 5

Mean Percent Errors as a Function of Group, Flanker Similarity, Attentional Focus, and Flanker Compatibility in Experiment 2

\begin{tabular}{|c|c|c|c|c|c|c|c|c|c|c|c|c|}
\hline & \multicolumn{6}{|c|}{ Dissimilar } & \multicolumn{6}{|c|}{ Similar } \\
\hline & \multicolumn{3}{|c|}{ Narrow } & \multicolumn{3}{|c|}{ Wide } & \multicolumn{3}{|c|}{ Narrow } & \multicolumn{3}{|c|}{ Wide } \\
\hline & $\mathrm{C}$ & $\mathrm{N}$ & I & $\mathrm{C}$ & $\mathbf{N}$ & I & $\mathrm{C}$ & $\mathrm{N}$ & $I$ & $\mathrm{C}$ & $\mathrm{N}$ & I \\
\hline \multicolumn{13}{|c|}{ Young } \\
\hline$M$ & .027 & .025 & .044 & .010 & .022 & .042 & .034 & .037 & .061 & .020 & .044 & .051 \\
\hline$S E$ & .009 & .008 & .012 & .004 & .008 & .009 & .014 & .012 & .016 & .008 & .013 & .018 \\
\hline \multicolumn{13}{|c|}{ Young-old } \\
\hline$M$ & .028 & .008 & .033 & .003 & .022 & .031 & .031 & .022 & .014 & .011 & .025 & .031 \\
\hline$S E$ & .009 & .004 & .017 & .003 & .009 & .008 & .009 & .007 & .007 & .005 & .011 & .008 \\
\hline \multicolumn{13}{|c|}{ Old-old } \\
\hline$M$ & .023 & .008 & .021 & .013 & .016 & .036 & .044 & .065 & .042 & .023 & .057 & .052 \\
\hline$S E$ & .008 & .004 & .008 & .005 & .007 & .011 & .010 & .018 & .010 & .011 & .015 & .008 \\
\hline
\end{tabular}




\section{Error Analyses}

Table 5 shows the mean error rates for each group and condition. First, the error rates are, in general, smaller for the dissimilar flanker condition than for the similar flanker condition across all conditions. Second, the error rates increase across the congruent, neutral, and incongruent conditions. Third, a facilitation effect is consistently present in the wide focus of attention condition, but not in the narrow focus of attention condition. Fourth, an interference effect is consistently present for the dissimilar flanker condition, but not for the similar flanker condition.

These observations were supported by an overall $3 \times 2$ $\times 2 \times 3$ mixed factor ANOVA, with age (young, youngold, old-old) as a between-subjects factor and similarity (dissimilar, similar), focus (narrow, wide), and flanker (congruent, incongruent, neutral) as within-subjects factors. The results yielded main effects of similarity $\left[F(1,45)=12.65, M S_{\mathrm{e}}=0.002, p<.0009\right]$, which indicated that participants produced more errors in the similar than in the dissimilar flanker condition, and flanker $\left[F(2,90)=8.27, M S_{\mathrm{e}}=0.001, p<.0005\right]$, which indicated that errors increased across the congruent, neutral, and incongruent conditions. The age $\times$ similarity interaction was also reliable, $\left[F(2,45)=3.62, M S_{\mathrm{e}}=0.002\right.$, $p<.03]$. Although fewer errors were produced overall in the dissimilar than in the similar flanker condition, post hoc testing revealed that the magnitude of this difference was reliable for the old-old adults $(p<.0008)$, but not the young or young-old adults $(p s>.05)$. The similarity $\times$ flanker interaction $\left[F(2,90)=4.47, M S_{\mathrm{e}}=0.001, p<\right.$ $.01]$, and the focus $\times$ flanker interaction $[F(2,90)=4.84$, $\left.M S_{\mathrm{e}}=0.002, p<.01\right]$, were both reliable, but neither interacted with age $(p s>.18)$. Neither of these interactions was analyzed further, given the very small differences in error rate between conditions. The reader should note that, in general, the pattern is similar to that for the reaction time data. None of the other interactions was reliable (all ps > .18).

\section{Discussion}

The results of Experiment 2 replicate those from the narrow interletter distance condition of Experiment 1. As in to Experiment 1, overall reaction times to the targets in the similar condition were slower than those to the targets in the dissimilar condition. This is consistent with a greater confusability of the similar than of the dissimilar targets (Keren \& Baggen, 1981) and a slower availability of local than of global features (Smid et al., 1991). Moreover, although the old-old adults were reliably slower to respond to similar than to dissimilar targets than either the young or the young-old adults in the unscaled analysis, this difference did not reach significance after adjusting for scaling effects from age differences in overall speed of processing (Cerella \& Hale, 1994). In contrast, the error data did reveal that the oldold adults produced more errors in the similar than in the dissimilar condition, whereas this difference was unreliable for either the young or the young-old adults. However, these data must be interpreted with caution, because an inspection of the error rate in the similar condition was comparable for the young and the old-old adults. Thus, the interaction resulted more from the fact that the old-old adults produced relatively more errors in the similar than in the dissimilar condition than did the other two groups. To examine whether an age-related decrease in visual acuity may have contributed to these results, two simple regression analyses were calculated across all participants, to examine whether the measure of visual acuity predicted the percentage of overall error for the dissimilar and similar targets. Results showed no effect of visual acuity for either the dissimilar $(d f=46$, $r=-.14, p=.35)$ or the similar targets $(d f=46, r=$ $.02, p=.88$ ). Thus, age-related decrements in sensory processing are not contributing to the pattern of the data. Rather, the overall pattern of the results suggests that the central perceptual processes underlying target identification may be compromised by advanced age.

The reaction time data showed that all three groups produced reliable and similar-sized facilitation effects that were uninfluenced by a narrow or a wide focus of attention or by target similarity (B. A. Eriksen \& C. W. Eriksen, 1974; Flowers, 1990). With regard to the interference effect, the reaction time results showed that the magnitude was reliably larger for the dissimilar than for the similar target response set for all three groups and was uninfluenced by the manipulation of attentional focus. As in to Experiment 1, an inspection of Figures 1 and 2 suggests that the decrease in the magnitude of the interference effect as a function of increasing target similarity is due to an increase in response time to similar targets in the neutral condition, rather than to a decrease in the incongruent condition. These results replicate the narrow interletter distance condition of Experiment 1 with a modified stimulus set and establish the generality of the finding. The results also revealed an age-related decrement that varied as a function of target similarity. That is, for the dissimilar target set, the results showed a reliable interference effect that was of a similar magnitude across all three groups, which replicates the majority of previous studies using unrelated target stimuli (e.g., Faust et al., 1995; Kramer et al., 1994; Plude \& Hoyer, 1986). In contrast, for the similar target set, there was an age-related reduction in the magnitude of the interference effect, but only for advanced age. An inspection of Figure 2 shows that this reduction resulted from a disproportionate increase in response times to the neutral targets, rather than from a decrease in response times to incongruent targets. Here also, to examine whether an age-related decrease in visual acuity may have contributed to these results, four simple regression analyses were calculated across all participants, to examine whether the measure of visual acuity predicted the magnitude of the interference effect for the four similarity $x$ 
focus conditions. The results showed no effect of visual acuity on the magnitude of the interference effect for either the dissimilar (narrow focus, $d f=46, r=.02, p=$ .91 ; wide focus, $d f=46, r=.23, p=.11$ ) or the simi$\operatorname{lar}$ (narrow focus, $d f=46, r=.04, p=.77$; wide focus, $d f=46, r=-.009, p=.95)$ targets. These results suggest that the older adults processed the target-flanker arrays as efficiently as the young adults in the dissimilar condition and provide evidence against the notion that the diminished interference effect for the old-old adults in the similar condition is due simply to a decrease in perceptual processing speed resulting from an age-related decline in visual acuity (Cerella, 1985; Wright \& Elias, 1979). In sum, the interference data are consistent with the notion that advanced age may impair the perceptual availability of local, but not global, shape information. However, consistent with previous studies, there is little evidence in support of an age-related impairment in the processes underlying response activation (Faust et al., 1995; Kramer et al., 1994).

Finally, the results also revealed that the overall response latencies were shorter in the narrow focus condition than in the wide focus condition (LaBerge \& Brown, 1989). However, in contrast to LaBerge et al. (1991), the manipulation of attentional focus had no influence on the interference effects for any of the three groups. Although the reason for this discrepancy is unclear, their task of requiring participants to identify a briefly presented letter centered in a 17-letter array of similar letters prior to responding to a target display may have been more effective than the present task in narrowing the focus of attention around the target. The reviewers raised the question of whether the focus tasks may have produced forward masking, with the letter task producing less than the word task. However, this seems unlikely. First, the probability of forward masking operating is low for both the young and the older adults. Di Lollo (1980, Experiment 4) has shown that the influence of a forward mask on a 20 -msec target decreases dramatically with mask durations longer than $100 \mathrm{msec}$. Both Coyne (1981) and Schlapfer, Groner, Lavoyer, and Fisch (1991) have shown that the critical interstimulus-interval for older adults (65-80) to escape masking is approximately $45 \mathrm{msec}$ later than that for young adults (critical ISI $=0$ ) with a $100-\mathrm{msec}$ mask and a $20-\mathrm{msec}$ target. Recall that, in the present task, the duration of the focus letter/word was $165 \mathrm{msec}$, and the target display duration was $240 \mathrm{msec}$. As such, any forward masking would be minimal, even for the older adults, because of the small residual visual persistence of the focus stimulus and the long target display duration. Second, the results suggest that the interference effect is not modulated by target-flanker similarity, but rather by target similarity. Thus, to the extent that masking was influencing the response times, it should be similar in both focus conditions. Yet there was a difference in overall response times between the narrow and the wide focus conditions that did not interact with age or the other factors. Although inconclusive, the overall slowing of response times in the wide focus condition may be related to the time required to change from a wide to a narrow focus of attention or to the extra processing time required to read a word than to read a single letter and then to switch to the target task.

\section{GENERAL DISCUSSION}

The present experiments yielded four main results. First, Experiments 1 and 2 both produced reliable overall facilitation effects in the response times that did not interact reliably with the particular targets used or the interletter distance (see, e.g., Flowers, 1990). In addition, consistent with previous distractor interference studies, there was no effect of age (Faust et al.; 1995; Spieler et al., 1996; Sullivan, Faust, \& Balota, 1995). Second, with regard to the interference effect, the response time results from Experiment 1 produced a reliable interaction between the similarity of the target response set and the interletter distance. That is, the magnitude of the effect was reliably smaller in the visually similar than in the visually dissimilar condition, but only at a narrow interletter distance. At a wide interletter distance, there was no difference between these two conditions. Experiment 2 replicated the finding of a larger interference effect for visually dissimilar than for visually similar targets at a narrow interletter distance with a different stimulus set. Third, the results of Experiment 2 also revealed an effect of advanced age. The old-old adults responded more slowly and produced more errors overall to the similar than to the dissimilar targets than did either the young or the young-old adults. In addition, the response time data showed that, in the dissimilar flanker condition, all three groups produced a reliable and similarsized interference effect. However, for the similar flanker condition, the old-old adults failed to produce a reliable effect, whereas the magnitude of this effect was reliable and of a similar size in both the young and the young-old adults. Finally, Experiment 2 showed that responses were shorter in the narrow than in the wide focus-of-attention condition but that this did not interact with age or any of the other conditions. The following discussion focuses on the main findings with regard to the interference effect.

\section{Selective Attention in Young Adults}

As was stated above, the literature provides support for the notion that there are two sources of slowing or interference underlying the ability to select a target in the presence of flankers. One source is associated with the enhanced function of a spatial filter that operates during early perceptual processing to facilitate identification of a target that occurs in the presence of visually similar (and response neutral) flankers (LaBerge, 1995; LaBerge \& Brown, 1989), and the other is associated with a competition for response activation (Coles et al., 1985; B. A. Eriksen \& C. W. Eriksen, 1974; C. W. Eriksen \& B. A. Eriksen, 1979; Smid et al., 1991). The first question addressed by this study was whether these two sources 
functionally interact with each other. Two hypotheses were proposed on the basis of the notion that increasing target-flanker similarity would enhance spatial filtering and slow target identification. One was that enhanced spatial filtering of the target would allow the incongruent flanker more time to activate the competing response (Ridderinkhof et al., 1995). This would result in a larger interference effect in the similar than in the dissimilar condition. The other was that enhanced spatial filtering would reduce the perceptual availability of the flanker identity (LaBerge \& Brown, 1989; LaBerge et al., 1991) or its response activation (Coles et al., 1992; Marteniuk $\&$ MacKenzie, 1980). The results of Experiments 1 and 2 supported neither of these hypotheses.

Although responses were, overall, slower to similar than to dissimilar targets, the first hypothesis can be rejected, because the interference effect was smaller in the similar than in the dissimilar condition when the interletter distance was narrow. However, it is important to note that this hypothesis cannot be rejected completely, because studies have shown that increasing or decreasing the response activation of the flanker, relative to the target, can modulate the magnitude of the interference effect (e.g., C. W. Eriksen \& Schultz, 1979; Ridderinkhof et al., 1995; Schwarz \& Mecklinger, 1995). For example, Ridderinkhof et al. (Experiment 3 ) varied the size of the target (i.e., small/large), relative to a constant flanker size, and found that response times were slower, but the interference effect (incongruent minus neutral) was larger for small than for large targets. Presumably, under these conditions, large flankers produced a greater response activation, relative to the small target.

The second hypothesis can be rejected because the decrease in the interference effect that was observed in the similar condition is not consistent with an enhanced spatial filtering that would cause a reduction in the competing response channel's activation. That is, in Experiment 1 , at both the narrow and the wide interletter distance, and in Experiment 2, response times were faster to targets in the dissimilar neutral than in the similar neutral condition, even though the flankers were equally unrelated to the targets. In contrast, there was essentially no difference in response times to targets in the similar and dissimilar incongruent conditions, but only at the narrow interletter distance. At the wide interletter distance, the results from Experiment 1 showed that response times were faster to dissimilar than to similar targets. The faster response times to dissimilar than to similar targets in the neutral condition can be attributed to a faster perceptual availability and selection of global versus local feature information, as well as to a response competition arising from the shared global feature of the similar targets (Smid et al., 1996; Smid et al., 1991). However, the results from the incongruent condition suggest that, in the presence of strong response competition, this benefit is reduced. These results raise the question of why the relative magnitude of response competition modulates the benefit of selection based on global shape informa- tion? Although a priority assignment for selection based on global or local features was not specifically manipulated by varying instructional set in the present experiments, the overall results are, at minimum, consistent with the notion that global information was available and selected earlier than local information. Moreover, both the continuous flow model of processing (C. W. Eriksen \& Schultz, 1979) and the more recent asynchronous discrete coding model proposed by Miller $(1982,1988)$ suggest that partial information can be used for a response prior to full stimulus identification. However, neither of these models can account for the more recent finding that the priority assignment of partial information during response selection appears to be under the strategic control of a central executive mechanism (Allport, 1987; Coles et al., 1991; Gratton, Coles, \& Donchin, 1992; Smid et al., 1996). That is, any relevant partial information is not necessarily used to activate a response as soon as it becomes available in perception. The results from the incongruent condition of Experiment 1 suggest that, when competition is strong at the narrow interletter distance and the probability of an error high, even though the global shape information may have been available, the participants may have strategically delayed selection, to avoid responding in error. Indeed, analyses of conditional accuracy functions have shown that selection errors increase disproportionately in incongruent conditions as response time decreases (e.g., Coles et al., 1985; Gratton et al., 1992). In contrast, at the wide interletter distance, where the response competition is reduced, participants may have adopted a less conservative response strategy that allowed their selection to benefit from the earlier availability of global shape information.

In sum, the fact that target-flanker similarity had little effect on the magnitude of the interference effect is consistent with the more recent proposal that the spatial filter may not perform a gate-gain function but, rather, may only enhance the flow of information coming from the target location when selection is difficult (LaBerge, 1995). The present results provide converging evidence for this notion by suggesting that enhanced spatial filtering does not limit the flow of perceptual information from the competing flanker to its corresponding response channel. Thus, it does not appear that the enhanced operation of the spatial filter, at least as a result of increasing target-flanker similarity, modulates the magnitude of response competition, as was originally proposed. Rather, the results suggest that the decrease in the interference effect resulted from a functional interaction between the perceptual availability of partial information and the magnitude of response competition (Coles et al., 1991; Gratton et al., 1992; Smid et al., 1996).

\section{Selective Attention in Aging}

The results of Experiment 2 revealed no age-related decline in the magnitude of the interference effect for the dissimilar target response set. The lack of an interaction 
suggested that there is no age-related reduction in the availability of global shape information or in the processes underlying response activation (Faust et al., 1995; Kramer et al., 1994). In contrast, for the similar target condition, the results showed a reliable decrease in the interference effect for advanced age that resulted from slower reaction times to targets in the neutral condition, with little difference between groups in response times to incongruent targets. On the one hand, the results from the neutral condition are consistent with the notion that advanced age may reduce the availability of local shape information, as well as with studies suggesting that age may produce a higher baseline of internal perceptual noise that impairs the ability to discriminate between similar letters (Allen et al., 1993; Kreuger \& Allen, 1987; Madden et al., 1994; see, also, Allen et al., 1994). On the other hand, the old-old adults also may have adopted a more conservative response selection criterion for the similar target response set (Zeef et al., 1996). However, the similar response times of the three age groups to the incongruent targets suggest that this may not have occurred. Further research is currently underway in an effort to obtain converging evidence in support of an age-related decrement in the perceptual availability of local information and the strategic control of priority assignment of response selection.

\section{REFERENCES}

Allen, P. A.,WEBER, T. A., \& MAdDEN, D. J. (1994). Adult age differences in attention: Filtering or selection? Journals of Gerontology, 49, P213-P222.

Allen, P. A.,Weber, T. A., \& MaY, N. (1993). Age differences in letter and color matching. Journals of Gerontology, 48, P69-P77.

ALLPORT, D. A. (1987). Selection for action: Some behavioral and neurophysiological considerations of attention and action. In $\mathrm{H}$. Heuer \& A. F. Sanders (Eds.), Perspectives on perception and action. Hillsdale, NJ: Erlbaum.

BALOTA, D. A., \& DuChEK, J. M. (1991). Semantic priming effects, lexical repetition effects, and contextual disambiguation effects in healthy aged individuals and individuals with senile dementia of the Alzheimer type. Brain \& Language, 40, 181-201.

BJORK, E. L., \& MURRAY, J. T. (1977). On the nature of input channels in visual processing. Psychological Review, 84, 472-484.

Cerella, J. (1985). Age-related decline in extrafoveal letter perception. Journal of Gerontology, 40, 727-736.

Cerella, J., \& Hale, S. (1994). The rise and fall in information processing rates over the life span. Acta Psychologica, 86, 109-197.

Cohen, J., MacWhinney, B., Flatt, M., \& Provost, J. (1993). PsyScope: An interactive graphical system for designing and controlling experiments in the psychology laboratory using Macintosh computers. Behavior Research Methods, Instruments, \& Computers, 25, 257-271

Coles, M. G. H., De Jong, R., Gehring, W. J., \& Gratton, G. (1991). Continuous versus discrete information processing: Evidence from movement-related potentials. In C. H. M. Brunia, G. Mulder, \& M. N. Verbaten (Eds.), Event-related brain research (Electroencephalography \& Clinical Neurophysiology, Suppl. 42). Amsterdam: Elsevier. Coles, M. G. H., Gehring, W. J., Gratton, G., \& DonChin, E. (1992). Response activation and verification: A psychophysiological analysis. In G. E. Stelmach \& J. Requin (Eds.), Tutorials in motor behavior II (Advances in Psychology, Vol. 87, pp. 779-792). Amsterdam: Elsevier.

Coles, M. G. H., Gratton, G., Bashore, T. R., Eriksen, C. W., \& Donchin, E. (1985). A psycho-physiological investigation of the continuous flow model of human processing. Journal of Experimental Psychology: Human Perception \& Performance, 11, $529-553$.

CoYNE, A. C. (1981). Age differences and practice in forward visual masking. Journal of Gerontology, 36, 730-732.

De Jong, R., Wierda, M., Mulder, G., \& Mulder, L. (1988). The use of partial information in response processing. Journal of Experimental Psychology: Human Perception \& Performance, 14, 682-692.

Di LoLLo, V. (1980). Temporal integration in visual memory. Journal of Experimental Psychology: General, 109, 75-97.

ERIKSEN, B. A., \& Eriksen, C. W. (1974). Effects of noise letters upon the identification of a target letter in a nonsearch task. Perception \& Psychophysics, 16, 143-149.

ERIKSEN, C. W., \& ERIKSEN, B. A. (1979). Target redundancy in visual search: Do repetitions of the target within the display impair processing? Perception \& Psychophysics, 26, 195-205.

ERIKSEN, C. W., \& SCHULTZ, D. W. (1979). Information processing in visual search: A continuous flow conception and experimental results. Perception \& Psychophysics, 25, 249-263.

EsTES, W. K. (1972). Interactions of signal and background variables in visual processing. Perception \& Psychophysics, 12, 278-286.

ESTES, W. K. (1982). Similarity-related channel interactions in visual processing. Journal of Experimental Psychology: Human Perception $\&$ Performance, 8, 353-382.

Faust, M. E., Balota, D. A., \& DucheK, J. M. (1995, November). Interference and negative priming: Flanker task performance in dementia of the Alzheimer type (DAT) and normal aging. Poster presented at the 36th Annual Meeting of the Psychonomic Society, Los Angeles.

FLowers, J. H. (1990). Priming effects in perceptual classification. Perception \& Psychophysics, 47, 135-148.

Folstein, M. F., Folstein, S. E., \& McHugh, P. R. (1975). "Minimental state": A practical method for grading the cognitive state of patients for the clinician. Journal of Psychiatric Research, 12, 189198.

Gratton, G., Coles, M. G. H., \& Donchin, E. (1992). Optimizing the use of information: Strategic control of activation of responses. Journal of Experimental Psychology: General, 121, 480-506.

Gratton, G., Coles, M. G. H., Sirevaag, E. T., Eriksen, C. W., \& Donchin, E. (1988). Pre- and post-stimulus activation of response channels: A psychophysiological analysis. Journal of Experimental Psychology: Human Perception \& Performance, 14, 331-344.

Greenwood, P. M., Parasuraman, R., \& Alexander, G. E. (1997). Controlling the focus of spatial attention during visual search: Effects of advanced aging and Alzheimer disease. Neuropsychology, 11, 3-12.

Hartley, A. A., \& McKenzie, C. R. (1991). Attentional and perceptual contributions to the identification of extrafoveal stimuli: Adult age comparisons. Journals of Gerontology, 46, P202-P206.

KEREN, G., \& BAGGEN, S. (1981). Recognition models of alphanumeric characters. Perception \& Psychophysics, 29, 234-246.

KOPP, B., Rist, F., \& MATTLER, U. (1996). N200 in the flanker task as a neurobehavioral tool for investigating executive control. Psychophysiology, 33, 282-294.

Kramer, A. F., Humphrey, D. G., Larish, J. F., \& Logan, G. D. (1994). Aging and inhibition: Beyond a unitary view of inhibitory processing in attention. Psychology \& Aging, 9, 491-512.

KruEger, L. E., \& ALLEN, P. A. (1987). Same-different judgments of foveal and parafoveal letter pairs by older adults. Perception \& Psychophysics, 41, 329-334.

LABERGE, D. (1994). Quantitative models of attention and response processes in shape identification tasks. Journal of Mathematical Psychology, 38, 198-243.

LABERGE, D. (1995). Computational and anatomical models of selective attention in object identification. In M. S. Gazzaniga, (Ed.), The cognitive neurosciences (pp. 649-662). Cambridge. MA: MIT Press.

LABERGE, D., \& Brown, V. (1989). Theory of attentional operations in shape identification. Psychological Review, 96, 101-124.

LaBerge, D., Brown, V., Carter, M., Bash, D. \& Hartley, A. (1991). Reducing the effects of adjacent distractors by narrowing attention. Journal of Experimental Psychology: Human Perception \& Performance, 17, 65-67. 
LAviE, N. (1997). Visual feature integration and focused attention: Response competition from multiple distractor features. Perception \& Psychophysics, 59, 543-556.

Luck, S. J., \& Hillyard, S. A. (1994). Spatial filtering during visual search: Evidence from human electrophysiology. Journal of Experimental Psychology: Human Perception \& Performance, 20, 10001014.

MADDEN, D. J. (1992). Selective attention and visual search: Revision of an allocation model and application to age differences. Journal of Experimental Psychology: Human Perception \& Performance, 18, 821-836.

Madden, D. J., Connelly, L., \& Pierce, T. W. (1994). Adult age difference in shifting focused attention. Psychology \& Aging, 9, 528538 .

Madden, D. J., Pierce, T. W., \& Allen, P. A. (1993). Age-related slowing and the time course of semantic priming in visual word identification. Psychology \& Aging, 8, 490-507.

MarTeniuk, R. G., \& MaCKenZIE, C. L. (1980). A preliminary theory of two hand coordinated control. In G. E. Stelmach \& J. Requin (Eds.), Tutorials in motor behavior (pp. 185-197). Amsterdam: North-Holland.

MILLER, J. (1982). Discrete versus continuous stage models of human information processing: In search of partial output. Journal of Experimental Psychology: Human Perception \& Performance, 8, 273296.

MILLER, J. (1988). Discrete and continuous models of human information processing: Theoretical distinctions and empirical results. Acta Psychologica, 67, 191-257.

Miller J., Coles M. G. H., \& Chakraborty, S. (1996). Dissociation between behavioral and psychophysiological measures of response preparation. Acta Psychologica, 94, 189-208.

Miller, J., \& HACKLEY, S. A. (1992). Electrophysiological evidence for temporal overlap among contingent mental processes. Journal of Experimental Psychology: General, 121, 195-209.

Myerson, Hale, S., Wagstaff, D., Poon, L. W., \& Smith, G. A. (1990). The information-loss model: A mathematical theory of agerelated cognitive slowing. Psychological Review, 97, 475-487.

Navon, D. (1977). Forest before trees: The precedence of global features in visual perception. Cognitive Psychology, 9, 353-383.

Osman, A., Bashore, T. R., Coles, M. G. H., Donchin, E., \& Meyer, D. E. (1988). A psychophysiological study of response preparation based on partial information [Abstract]. Psychophysiology, 25, 425.

Osman, A., Bashore, T. R., Coles, M. G. H., Donchin, E., \& Meyer, D. E. (1992). On the transmission of partial information: Interference from movement-related brain potentials. Journal of Experimental Psychology: Human Perception \& Performance, 18, 217-232.

Paquet, L., \& Lortie, C. (1990). Evidence for early selection: Precuing target location reduces interference from same-category distractors. Perception \& Psychophysics, 48, 383-388.

Plude, D. J., \& HoYer, W. J. (1986). Age and the selectivity of visual information processing. Psychology \& Aging, 1, 4-10.

Pomerantz, J. R. (1983). Global and local precedence: Selective attention in form and motion perception. Journal of Experimental Psychology: General, 112, 516-540.

Ridderinkhof, K. R. \& VAN der Molen, M. W. (1995). When global information and local information collide: $A$ brain potential analysis of the locus of interference effects. Biological Psychology, 41, 29-53.

Ridderinkhof, K. R., VAN der Molen, M. W., \& Bashore, T. R. (1995). Limits on the application of additive factors logic: Violations of stage robustness suggest a dual-process architecture to explain flanker effects on target processing. Acta Psychologica, 90, 29-48.

Schlapfer, T. E., Groner, M., Lavoyer, E., \& Fisch, H.-U. (1991). Visual masking: A reliable measure for the assessment of cognitive dysfunction in the elderly? Journals of Gerontology, 46, P157-P161.
Schwarz, W., \& MECKLinger, A. (1995). Relationship between flanker identifiability and compatibility effect. Perception \& Psychophysics, 57, 1045-1052.

SEKULER, R., \& BALL, K. (1986). Visual localization: Age and practice. Journal of the Optical Society of America A, 3, 864-867.

Smid, H. G. O. M., Bocker, K. B. E., van Touw, D. A., Mulder, G., \& BRUNIA, C. H. M. (1996). A psychophyiological investigation of the selection and the use of partial stimulus information in response choice. Journal of Experimental Psychology: Human Perception \& Performance, 22, 3-24.

Smid, H. G. O. M., \& Heinze, J. J. (1997). An electrophysiological study of the selection of the color and shape of alphanumeric characters in response choice. Biological Psychology, 44, 161-185.

Smid, H. G. O. M., Lamain, W., Hogeboom, M. M., Mulder, G., \& MULDER, L. J. M. (1991). Psychophysiological evidence for continuous information transmission between visual search and response processes. Journal of Experimental Psychology: Human Perception \& Performance, 17, 696-714.

Smid, H. G. O. M, Mulder, G., \& Mulder, L. J. M. (1990). Selective response activation can begin before stimulus recognition is complete: A psychophysiological and error analysis of continuous flow. Acta Psychologica, 74, 169-201.

Smid, H. G. O. M, Mulder, G., Mulder, L. J. M., \& Brands, G. (1992). A psychophyiological study of the use of partial stimulus information in stimulus-response translation. Journal of Experimental Psychology: Human Perception \& Performance, 18, $1101-1119$.

Spieler, D. H., Balota, D. A., \& Faust, M. E. (1996). Stroop performance in healthy younger and older adults, and in individuals with dementia of the Alzheimer's type. Journal of Experimental Psychology: Human Perception \& Performance, 22, 461-479.

Sullivan, M. P., \& Faust, M. E. (1993), Evidence for identity inhibition during selective attention in old adults. Psychology \& Aging, 8, 589-598.

Sullivan, M. P., Faust, M. E., \& Balota, D. A. (1995). Identity negative priming in older adults and individuals with dementia of the Alzheimer's type. Neuropsychology, 9, 537-555.

Wright, L. L., \& ELIAS, J. W. (1979). Age differences in the effects of perceptual noise. Journal of Gerontology, 34, 704-708.

YANTIS, S., \& JoHNSTON, J. C. (1990). On the locus of visual selection: Evidence from focused attention tasks. Journal of Experimental Psychology: Human Perception \& Performance, 6, 135-149.

YEH, Y.-Y., \& ERIKSEN, C. W. (1984). Name codes and features in the discrimination of letter forms. Perception \& Psychophysics, 36, 225233.

ZEEF, E. J., \& KoK, A. (1993). Age-related differences in the timing of stimulus and response processes during visual selective attention: Performance and psychophysiological analyses. Psychophysiology, 30, 138-151.

Zeef, E. J., Sonke, C. J., KoK, A., Buiten, M. M., \& Kenemans, L. J. (1996). Perceptual factors affecting age-related differences in focused attention: Performance and psychophysiological analyses. Psychophysiology, 33, 555-565.

\section{NOTE}

1. Note that both the benefit from the earlier availability of global feature information and the slowing because of the activation of competing responses based on a shared global feature would be less likely to influence the response times to dissimilar and similar targets in the congruent condition, in which the flankers share the same identity.

(Manuscript received October 8, 1997; revision accepted for publication May 4, 1998.) 